\title{
Resuscitation-fluid replacement
}

\author{
W. G. Prout \\ M.B., F.R.C.S. \\ Surgical Registrar, \\ St Peter's Hospital, Chertsey, \\ and St Thomas' Hospital, London
}

\author{
R. VAughan Jones \\ M.B., M.R.C.P., M.C.Path. \\ Consultant Pathologist,
}

North West Surrey Group Laboratory

\section{St Peter's Hospital, Chertsey}

THIS short account will be confined to the management of circulatory failure in the first few hours after reception of the patient in a Casualty Department. Where shock is due to trauma the cause will usually be obvious, but many shocked cases brought to Casualty Departments suffer from other diseases in which circulatory failure may be complex in origin. For this reason we have also discussed non-traumatic causes.

\section{Traumatic shock}

It is generally agreed that reduction in the circulating blood volume is the main factor in the production of traumatic shock. When external or internal haemorrhage takes place, the fluid lost is, of course, blood. When there is extensive burning an increase in capillary permeability leads to a massive exudation of plasma-like fluid with reduction in the plasma and extracellular fluid volumes. Crushing injuries may cause not only frank haemorrhage but also the accumulation of a plasma-like inflammatory exudate in the damaged tissues with reduction in the plasma volume and hence the blood volume.

\section{Electrolyte changes}

After trauma in the normal subject oliguria and reduced renal sodium output are the rule, whereas renal potassium output is increased. Plasma sodium levels are reduced but this does not indicate sodium depletion and is not an indication for therapy with isotonic or hypertonic saline (Sevitt, 1966). Plasma potassium levels may rise, sometimes rapidly if there has been considerable damage to muscle. If oliguria persists hyperkalaemia may necessitate the administration of resins or some form of dialysis (Gallagher \& Polak, 1967).

\section{Terminology}

Shock, a term hallowed by some 200 years usage, defies precise definition, for it represents not a single syndrome but a collection of syn- dromes with no common single clinical manifestation.

Bloch et al. (1966) define shock as a state of $\frac{\vec{\omega}}{\omega}$ progressive circulatory failure in which the cardiac output is insufficient to meet tissue requirements for nutrition, oxygenation or waste disposal. This definition serves to emphasize the basic pathological feature, that of defective tissue perfusion

For the different forms of shock, further terms have been introduced. Shires (1967) has suggested subdivision into haematogenic, neurogenic, vasogenic and cardiogenic forms, but these are terms without therapeutic implication. McGowan \& Walters (1966) point out that clinically two patterns of circulatory upset are most often seeg -cold hypotension and warm hypotension, terms first suggested by Grant \& Reeve (1951, p. 225).

\section{Cold hypotension}

This refers to classical traumatic shock characterized by low blood pressure (systolic pressure less than $100 \mathrm{mmHg}$ ), high pulse rate (greater than $100 / \mathrm{min}$ ) low pulse volume and usually cold pale extremities. Central venous pressure (CVP) is low.

Reduced cardiac output and peripheral arteriolar constriction are associated with this type of shock.

This condition may be the result of oligaemia, acute myocardial failure, pulmonary embolism, infection especially that due to Gram-negative organisms, or pancreatitis.

\section{Warm hypotension}

Here the blood pressure is low with high pulse rate and full pulse volume, while the extremities are commonly warm and dry. CVP is normal or a little reduced.

In this type of shock the cardiac output is probably undiminished but there is a decrease in arteriolar tone.

Warm hypotension is found in response to infection, pancreatitis, following treatment of cold hypotension, in response to drugs, e.g. anaesthetic 
agents and barbiturate or phenothiazine group overdosage, and in alcoholism. In the last two groups of patients circulatory reflexes are blocked (Barraclough \& Sharpey-Schafer, 1963) and shock may develop when they are subjected to relatively minor traumata.

It must be emphasized that these two states are not clear-cut subdivisions, and intermediates may be found: indeed, the patient may pass from one to the other during the course of an illness.

\section{Pathophysiology of shock}

The changes which occur in uncomplicated oligaemic shock are well known. Reduction of circulating blood volume stimulates baroreceptors causing an increase in the rate and force of the cardiac beat, constriction of veins, venules and of the regional peripheral arteriolar beds, all the result of adrenergic stimulation (Mollison, 1967, p. 153). The blood flow to the splanchnic area, skin, muscle and kidneys is considerably reduced and blood is diverted to the cerebral and coronary vessels (Freeman, 1963).

In healthy young adults without cardiopulmonary disease these changes occur after a loss of about $30 \%$ of the blood volume (approximately 3 pints): as the blood loss approaches $50 \%$ the compensatory vasoconstriction is no longer adequate and death is imminent if transfusion is withheld (Grant \& Reeve, 1951, p. 205).

\section{Irreversible shock}

In recent years much experimental and clinical attention has been directed to this state. Many patients who would formerly have come within this category are now effectively treated and the diagnosis of irreversible shock should only be made retrospectively when the patient dies of shock.

Nevertheless, the term is sometimes used loosely to denote a state of persistent circulatory failure despite adequate blood volume replacement. Perhaps a better term is 'refractory shock' (Smith \& Moore, 1962) from which the patient might recover or pass into true irreversible shock with ensuing death.

The mechanisms involved in irreversible shock are beyond the scope of this article-an excellent account is given by Bloch et al. (1966).

\section{Practical management of shock}

Shock from traumatic causes. In traumatic shock, oligaemia is the result of external or internal blood loss, or of plasma loss from damaged capillaries in the traumatized region. The several facets of resuscitation of the shocked patient are most conveniently considered separately.

\section{(a) Intravenous infusion}

In the severely injured patient, particularly if old or suffering from concurrent disease, monitoring of the central venous pressure is desirable and an intravenous catheter should be introduced so that its tip lies in a great vein.

If oligaemia and venoconstriction make percutaneous cannulation difficult, time should not be wasted on a prolonged search for a suitable vein ; instead a cut-down should be performed.

A 12-in. catheter may be introduced via the antecubital vein into the axillary or subclavian veins. If care is taken that the tip of the catheter does not impinge on the valve at the lower border of the subscapularis, an accurate measurement of the central venous pressure is obtained.

Note: If an Intracath (Bard-Davol) or Needle and Cathether (Portex) is used at the elbow, care must be taken that the needle cutting edge is guarded, and the elbow firmly splinted so that the catheter cannot be severed by play against the sharp end of the needle.

Some authors (Borow et al., 1965) have suggested using the external jugular or cephalic veins, but there may be difficulty in negotiating the valves which guard the terminations of those veins.

If none of these veins is suitable, percutaneous cannulation of the femoral vein is performed: the needle is introduced just below the skin crease, $1 \mathrm{~cm}$ medial to the femoral artery. It is passed in a backward and upward direction to enter the femoral vein where it is supported by the superior pubic ramus. Through it the catheter may be passed into the inferior vena cava. A greater incidence of thrombo-embolic phenomena make this route less desirable (Wilson et al., 1962).

Long saphenous cut-down at the ankle is technically easy but makes CVP measurement impossible.

\section{(b) Immediate investigations}

A specimen of blood for grouping and matching should be despatched to the laboratory as soon as possible. This does not, however, take precedence over infusing the patient, should direct venepuncture prove difficult.

Haemoglobin and haematocrit estimations are valuable as they provide a baseline for retrospective assessment even although they do not accurately reflect the blood loss until haemodilution has occurred over the first $48 \mathrm{hr}$.

Similarly, initial determination of the plasma electrolytes and blood urea may be useful, and a specimen of separated plasma, retained overnight in the refrigerator, may be analysed at a convenient time. 
(c) Fluids for infusion

Whole blood. Where haemorrhage has occurred blood is the correct replacement fluid, although some other fluid may have to be given while it is made ready. Unmatched blood should only be given in dire emergency and it clearly behoves'a new casualty officer to find out what arrangements exist in his hospital for the rapid matching of blood.

When very large quantities of stored blood are given rapidly, e.g. at the rate of $500 \mathrm{ml}$ in $5 \mathrm{~min}$, cardiac arrest may occur. Administration of $10 \mathrm{ml}$ of $10 \%$ calcium gluconate for each litre of blood transfused has been recommended (Bull, 1963a). For a discussion of this problem and methods of warming blood see Lancet (1966).

Plasma. In burns, plasma is perhaps the ideal replacement fluid although some writers advocate dextran (Wilkinson, 1960). Small-pool plasma carries a risk of hepatitis of less than $1 \%$ (Bull, 1963b), but supply is often a limiting factor in the use.

Dextran. Several kinds of dextran solution are available. Dextran Injection B.P. has an average molecular weight (M.W.) of 150,000 and has recently been designated Dextran 150. Blood sludging and capillary blocking were observed in experimental animals given such dextran, and significant histological damage, attributed to hypoxia, was found especially in the liver and myocardium (Ricketts, 1966).

Low-molecular weight dextrans (average 40,000) appear to have no sludging properties and are claimed to improve tissue perfusion when this is impaired (Lancet, 1964). They are much more rapidly excreted in the urine so that plasma volume expansion is relatively transient, compared with that achieved by other dextrans. Low molecular weight dextrans should not be given to dehydrated patients because of the risk of producing oliguria (Eliasson, 1963). They may occasionally cause renal failure in patients who are not dehydrated (Morgan, Little \& Evans, 1966). Their place in the treatment of shock is not yet clearly defined and the subject is reviewed by Mollison (1967, p. 177).

Dextran 110 (Ricketts, 1966) with an average M.W. of 110,000 has few of the larger molecules responsible for sludging but is well retained in the circulation. The Swedish and American dextrans of average M.W. 70,000 or 75,000 have a higher urinary excretion rate and are retained in the circulation for shorter periods.

We feel that Dextran 110 or dextrans of M.W. $70,000-75,000$ are the products of choice for resuscitation unless there are special rheological indications for low molecular weight dextran.
Abnormal bleeding has followed the use of large quantities of dextran (Hardisty \& Ingram, 1965). There is evidence that the bleeding tendency is most severe with fractions of large average molecular weight but no clear picture is available of the quantity of dextran which can be tolerated without causing bleeding. Mollison (1967, p. 175) suggests that in ordinary circumstances it is best to limit to 1 litre the amount of dextran given but it is clear that in the treatment of burns this amount has often been exceeded without side effects.

Saline. Saline will frequently be the fluid of first choice in resuscitation, its administration allowing blood to be taken, before dextran is administered, from veins which are no longer collapsed, or permitting time for plasma to be dissolved or blood to be matched. Saline is comparatively rapidly removed from the circulation.

Mannitol. Acute renal failure is often encountered following major trauma, e.g. $14 \%$ of American soldiers severely injured in the Korean War developed this condition (Bourne \& Cerny, 1964) emphasizing the importance of the kidney in shock.

Mannitol diuresis appears to protect the ischaemic kidney in the early phases of rena® failure before demonstrable tubule cell damage has occurred. Protection may be due to increase cardiac output (Camishion \& Fishman, 1964), increased renal blood flow (Teschan, Gagnon \& Murphy, 1963; Bourne \& Cerny, 1964) or irrigation of pigment particles or casts from the tubules (Mueller, 1965).

Although a view to the contrary has been expressed (Saito et al., 1965), we feel that mannitol should be given to all severely injured patients. Twenty-five grams of mannitol $(10 \%$ or $20 \%$ solution) may be rapidly infused when urgent resuscitation has been completed. This dose should not be repeated unless a flow of urine of at least $100 \mathrm{ml} / \mathrm{hr}$ results, when, after $6 \mathrm{hr}$, a further dose may be given.

Choice of fluid. Factors such as the haemoglobin concentration and state of hydration of the patient, which fluid has been lost and which are available will dictate which fluids ought to be administered. If dextran has been administered before a blood sample was taken for matching tests, the laboratory should be warned as rouleaux formation may be expected.

(d) Assessment of blood loss

As stated earlier, in a healthy young adult who has been injured, and shows signs of oligaemic shock, the blood loss will be of the order of 3 pints. For this reason, Jamieson \& Kay (1966a) suggest transfusing the patient till the systolic 
blood pressure reaches $100 \mathrm{mmHg}$ and then transfusing a further 2 pints.

In limb injuries, the relation between the size of the wound and the blood volume led Grant \& Reeve $(1951$, p. 197) to suggest that an area of damaged tissue less than the size of one hand represented a loss of less than $10 \%$ of the patient's blood volume; one to three hands, roughly $20-40 \%$; five hands, $50 \%$ approximately. Clarke \& Fisher (1956), finding the volume of a clenched hand to be about $500 \mathrm{ml}$, used this for estimating haematoma size. Thus, as a very rough guide, for each 'hand' or 'fist' of wound or haematoma, a pint of blood will have been lost. Clearly, this method of estimating blood loss will not take account of haemorrhage into the chest, the pelvis or the retroperitoneal tissues.

As up to 1.7 litres of blood may be lost in a closed fracture of femur (Clark, Topley \& Flear, $1955)$ and as much as half the blood volume in trunk fractures with visceral damage, the usual tendency is to under-transfuse these patients (Apley, 1963). The response to treatment is crucial and will provide an index of its adequacy.

Other methods of controlling fluid replacement are now available.

\section{Blood volume measurement}

The relative complexity of these estimations, and the time taken, have been reduced by computerized semi-automatic machines measuring the dilution of 125I- and 131I-labelled albumin. The expected blood volume can be calculated from the subject's height and weight (Nadler, Hidalgo \& Bloch, 1962) if the latter can be measured. This method has been championed by Fine (Friedman, Grable \& Fine, 1966), but there appear to be major objections to control of infusion therapy by repeated blood volume measurements.

Repeated venepuncture in the shocked patient, particularly if obese, may prove impossible. Furthermore, it is now recognized that the capacity of the circulation may increase following hypotension, trauma, infection and administration of drugs such as anaesthetic agents, alcohol, barbiturate or phenothiazine derivatives (MacLean, 1964 ; Barraclough \& Sharpey-Schafer, 1963). The fact that blood volume is 'normal' does not indicate that it is necessarily adequate for the circulatory demands at that particular time (McGowan \& Walters, 1963).

For these reasons, the use of central venous pressure monitoring as a guide to fluid replacement is to be recommended strongly.

\section{Central venous pressure (CVP)}

MacLean et al. (1965) emphasize that shock is a failure of blood flow, not blood pressure. If adequate blood flow and tissue perfusion are to be attained, the blood volume must be sufficient for the capacity of the circulation, whilst the cardiac pump must be able to maintain its flow.

All three of these factors are mirrored in the central venous pressure, so that it is an index of the circulating blood volume relative to the combined capacities of the heart pump and the vascular bed (Borow et al., 1965).

The normal range of CVP is from 6 to $17 \mathrm{~cm}$ of water above the mid-point of the heart, which is on a level with the mid-axillary line in the supine patient (Harkins, 1965). Whilst a single measurement may be used as a therapeutic pointer (see Table 1), observation of the changes which occur in response to therapy provides the best guide to fluid replacement.

TABLE 1

Therapy according to CVP

(after Borow et al., 1965)

\begin{tabular}{lll}
\hline CVP* & Inference & Therapy \\
\hline $0-5$ & Hypovolaemia & $\begin{array}{l}\text { Active replacement } \\
\text { of fluid }\end{array}$ \\
$6-12$ & $\begin{array}{l}\text { Possible } \\
\text { hypovolaemia }\end{array}$ & $\begin{array}{l}\text { Trial administration } \\
\text { of fluid }\end{array}$ \\
$>15$ & $\begin{array}{l}\text { Heart failure } \\
\text { or over- } \\
\text { transfusion }\end{array}$ & $\begin{array}{l}\text { Curtail fluid } \\
\text { administration } \\
\text { danger of } \\
\text { pulmonary oedema }\end{array}$ \\
\hline
\end{tabular}

*Central venous pressure: $\mathrm{cm}$ of $\mathrm{H}_{2} \mathrm{O}$ above mid-thoracic point.

The actual measurement of CVP has been greatly facilitated by the advent of the disposable venous manometer (Baxter, Capon-Heaton) (Hobbs, 1966). This is a double-ended transfusion giving-set, one arm of which is attached vertically to the drip-stand and used as a saline manometer. An external measuring-gauge introduced earlier by McGowan \& Walters (1963) now seems less satisfactory, having the disadvantage that nursing staff are unable to use it as readily as the saline manometer.

Measuring central venous pressure and arterial pressure, transfusion and infusion is controlled according to the therapeutic response:

(1) Rising systolic pressure: low or normal $C V P$. This occurs in the early treatment of shock due to oligaemia. The tendency to stop replacement prematurely must be avoided, remembering that normotension may be found with blood volume deficiencies of up to $30 \%$ (Grant \& Reeve, 1951, p. 198). Transfusion may, with advantage, be continued until 2 pints in excess of that 
required to establish an arterial pressure of $100 \mathrm{mmHg}$ systolic have been given (Jamieson \& Kay, 1966), and so that the CVP rises to the normal range. Otherwise the patient remains liable to return to the shocked state if further relatively small blood or plasma loss occurs.

(2) Persistent low systolic pressure: rapidly rising $C V P$. If, after the administration of a small volume (200-300 ml) of the appropriate intravenous fluid, the arterial pressure remains low, but the CVP starts to rise, the cause of the shock is not oligaemia.

(3) Persistent low systolic pressure: slowly rising $C V P$. This is not seen in oligaemic shock, unless delay in instituting treatment has caused it to become 'refractory' or 'irreversible' (see below).

(4) Low systolic pressure: high CVP. This may be found in cardiac disorders such as myocardial infarction, pulmonary embolism and in cardiac tamponade.

Treatment is directed at the cause along standard medical or surgical lines. Treatment of cardiogenic shock by intravenous infusion with peripheral vasodilators is under investigation, but its value is unproven (Brit. med. J., 1966).

The treatment of categories (2) and (3) is dealt with in the next section.

\section{Shock from non-traumatic causes}

Although the casualty officer is chiefly concerned with shock due to trauma, many cases of shock due to other causes are dealt with initially in Casualty Departments. A brief account of the management of fluid replacement in these patients is given.

- With the exception of those with severe uncontrolled haemorrhage, most hypotensive surgical patients will benefit from a period of rehydration and electrolyte correction. If administration of an anaesthetic is anticipated, it is particularly important that hypovolaemia should be corrected for the overall effect of the anaesthetic is to enlarge the vascular space and diminish compensatory reflexes (Wylie \& Churchill-Davidson, 1966). Low serum potassium should be corrected if muscle relaxants are to be used, although use of a nondepolarizing muscle relaxant in hypokalaemia does not necessarily result in prolonged neuromuscular block (Evans \& Gray, 1965).

Early adequate fluid replacement, with appropriate anti-bacterial therapy if there is an infective element in the cause of shock, will usually result in a satisfactory peripheral circulation, with a state of normotension or warm hypotension.

Delay in treatment may result in a response to intravenous therapy as seen in groups (2) and (3) above; persistent low systolic pressure and rising
CVP. The management of these patients where the cause of shock is uncertain follows the same general pattern, regardless of cause.

If an infection cannot be excluded, after blood culture large doses of antibacterial agents are given. The choice will depend upon the organism suspected, and its sensitivities if it is expected to be a hospital strain. Usually two antibacterial agents are given in combination.

Reduced tissue-perfusion leads to hypoxia and anaerobic metabolism, accumulation of lactate and pyruvate and a metabolic acidosis (Freeman, 1963). Correction of such an acidosis on the lines suggested by Astrup et al. (1960) is widely practised (MacLean et al., 1965; Borow et al., 1965 ; du Toit et al., 1966), although the view that clinical acidosis impairs myocardial efficiency has been disputed (Shires, 1967).

It is clear that many patients with traumatic shock who are adequately transfused do not develop a metabolic acidosis and require no such correction. In refractory shock, however, the acidosis should be corrected.

Plasma, blood, or other circulation expander is infused till the CVP approaches the upper limit of normal (unless there is a history of cardiac insufficiency when a lower level is recommended). If warm hypotension persists, or if cold hypotensio has become converted to warm hypotensio during this additional therapy, no further immediate action is taken. If cold hypotension persists, indicating poor peripheral tissue perfusion, certain other therapeutic agents may be used.

\section{(a) Phenoxybenzamine (dibenzyline)}

This is an $\alpha$-adrenergic blocking agent. Blockade of the $\alpha$-receptors, which are chiefly concerned with vasoconstriction, results in decreased peripheral resistance with increased blood flow, notably to the renal and splanchnic circulations (Nickerson, 1966, p. 550). As well as increasing tissue perfusion, the cardiac load is considerably decreased (Bloch et al., 1966). Also, movements of fluid from the pulmonary to the systemic circulation and from the interstitial to vascular compartments take place.

Nickerson $(1966$, p. 553) suggests that a dose of $1 \mathrm{mg} / \mathrm{kg}$ body weight is given intravenously in $500 \mathrm{ml}$ of normal saline or $5 \%$ dextrose over about $1 \mathrm{hr}$. By this time the effect is maximal and persists for up to 2 days. It affects only the $\alpha$-receptors and does not block the $\beta$-receptors. Once given it cannot be reversed.

The clinical use of this drug is described by Lillehei et al. (1964) and Eckenhoff \& Cooperman (1965). 


\section{(b) Hydrocortisone}

Hydrocortisone was initially used in shock as replacement therapy for supposed adrenal cortical failure. This does not, in fact, occur, and the only place for doses of the order $100-200 \mathrm{mg}$ is in the treatment of an Addisonian-type crisis.

Lillehei et al. (1964) have used massive doses (40-60 $\mathrm{mg} / \mathrm{kg}$ body weight) which appears to exert an $\alpha$-adrenergic blocking effect.

Smith \& Moore (1962) report no beneficial effect from this drug in small doses, and Walters (1967, personal communication) saw no beneficial effect in twelve of thirteen patients who were given massive doses after failing to respond to transfusion. The conventional form of $\alpha$-adrenergic blocker would seem a more hopeful prospect.

\section{(c) Isoprenaline}

Other workers have used isoprenaline in the management of the hypotensive patient with raised venous pressure (Maclean et al., 1966; Du Toit et al., 1966).

A $\beta$-adrenergic stimulator, this drug acts on the heart and increases cardiac output by direct action on rate and force of beat. Peripherally it causes arteriolar relaxation, chiefly in the muscle circulation, but also of the renal and splachnic beds to some degree. Improved tissue perfusion results.

One milligram of isoprenaline is diluted in $500 \mathrm{ml}$ of saline or $5 \%$ dextrose and $50-100 \mathrm{ml}$ infused every hour. The rate of infusion should not exceed that which raises the pulse rate above $110 / \mathrm{min}$, as higher rates may predispose to arrhythmias and decreased stroke volume (Maclean et al., 1965).

Note: It is of the utmost importance that if any of these three agents which expand the circulatory capacity is used, the patient must not be oligaemic before their administration. The reader is strongly recommended to consult the references cited before using the drugs.

Vasopressor agents such as adrenaline, noradrenaline or metaraminol should not be used in place of adequate blood volume replacement. They have no part to play in the treatment of oligaemic shock (Mollison, 1967, p. 153).

\section{Burns}

The severely burned patient is usually treated in a specialist centre, and a brief account only of the initial intravenous therapy is given.

The area of burning is estimated by Wallace's 'rule of nine': The head plus the separate upper limbs each account for $9 \%$ skin area, whilst the front of the trunk, back of the trunk and the whole leg are each covered by about $18 \%$ of the skin area (Wallace, 1951). A small child has a relatively larger head and smaller limbs. Intravenous therapy should be instituted in children with more than a $10 \%$ burn and in adults with a $15 \%$ or larger burn (Bull, 1963a). Moyer (1966, p. 353) points out that burns of less than $20 \%$ rarely produce shock, except in infants and very old people.

Although the traditional view is that therapy should be directed towards restoring blood volume (Mollison, 1967, pp. 169 et seq.), recently the importance of extravascular sodium deficiency has been stressed, and Moyer (1966, p. 349) expresses the view that this is the major cause of burn shock, regarding oligaemia as a minor cause. A series of cases with severe burns who made good recoveries when treated solely with large volumes of lactated Ringer's solution in spite of rising haematocrits, adds weight to the opinion.

In this country at present, plasma, plasma substitute and normal saline form the sheet anchor of the early therapy of burns. Dextran would seem an adequate substitute for plasma, though probably its use should be limited to 1 litre (see under infusion fluids).

The methods of deciding volume replacement have been reviewed by Bull (1963a).

Evans et al. (1952) suggest that $1 \mathrm{ml}$ of colloid $/ \%$ burn $/ \mathrm{kg}$ of body weight should be given in the first $24 \mathrm{hr}$ along with an equal volume of saline. Placing an upper limit of $50 \%$ on the burn to avoid the risk of pulmonary oedema, they report good results in sixty-eight patients.

Such a formula provides only the roughest guide. Further, although serial venous haematocrits, and urinary output may be measured, the variability of the individual response precludes their use as the only criteria on which transfusion may be based. The adequacy of fluid replacement should be assessed from the clinical condition of the patient and the parameters described earlier under traumatic shock.

Although in a full thickness burn of greater than $15 \%$ appreciable destruction of red cells occurs, there seems to be little advantage in early replacement of this loss (Topley \& Jackson, 1957) and transfusion of blood can wait until the anaemia appears.

\section{Summary}

The resuscitation of patients with peripheral circulatory failure using intravenous fluids has been reviewed.

\section{Acknowledgment}

We are grateful to Dr G. Walters who originally stimulated our interest in this subject. 


\section{References}

APLEY, A.G. (1963) A System of Orthopaedics and Fractures, p. 283. Butterworths, London.

Astrup, P., Jorgensen, K., SiggaArd-Anderson, O. \& ENGEL, K. (1960) The acid-base metabolism. Lancet, i, 1035.

Barraclough, M.A. \& Sharpey-SChafer, E.P. (1963) Hypotension from absent circulatory reflexes. Lancet, $\mathbf{i}, 489$.

Bloch, J.H., Dietzman, R.H., Pierce, C.H. \& Lillehei, R.C. (1966) Theories of the production of shock. Brit. J. Anaesth. 38, 234.

Borow, M., Aquilizan, L., Karusz, A. \& Stefanides, A. (1965) The use of central venous pressure as an accurate guide for body fluid replacement. Surg. Gynec. Obstet. $120,545$.

Bourne, C.W. \& CERNY, J.C. (1964) The role of mannitol in acute trauma. Univ. Mich. med. Cent. J. 30, 109.

Brit. med. J. (1966) Cardiogenic shock. Brit. med. J. ii, 481.

Bull, J.P. (1963a) Transfusion fluids. Ann. roy. Coll. Surg. 33, 175.

Bull, J.P. (1963b) Burns. Postgrad. med. J. 39, 717.

Camishon, R.C. \& FishmanN, N.H. (1964) Effect of mannitol on renal blood flow and cardiac output in haemorrhagic shock. Supplement 1 to Circulation, 29, 130.

Clarke, R. \& Fisher, M.R. (1956) Assessment of blood loss following injury. Brit. J. clin. Pract. 10, 746.

Clarke, R., Topley, E. \& Flear, C.T.G. (1955) Assessment of blood loss in civilian trauma. Lancet, i, 629.

Du ToIT, H.J., Du Pliess, J.M.E., Dommisse, J., Rorke, M.J., Theron, M.S. \& DE Villiers, V.P. (1966) Treatment of endotoxic shock with isoprenaline. Lancet, ii, 143.

ECKenhoff, J.E. \& CoOperman, L.H. (1965) The clinical application of phenoxybenzamine in shock and vasoconstrictive states. Surg. Gynec. Obstet. 121, 483.

Eliasson, R. (1963) Low Molecular Weight Dextran, p. 6. A symposium held at Royal Society of Medicine, London.

Evans, E.I., Purnell, O.J., Robinett, P.W., Batchelor, A. \& MARTIN, M. (1952) Fluid and electrolyte requirements in severe burns. Ann. Surg. 135, 804.

Evans, F.T. \& Gray, T.C. (1965) General Anaesthesia, Vol. 1, p. 548. Butterworths, London.

Freeman, J. (1963) Physiological effects of haemorrhage. Ann. roy. Coll. Surg. 33, 138.

Friedman, E., Grable, E. \& Fine, J. (1966) Central venous pressure and direct serial measurements as a guide in blood volume replacement. Lancet, ii, 609.

Gallagher, L. \& Polak, A. (1967) The management of acute renal failure. Hosp. Med. 1, 287.

Grant, R.T. \& ReEve, E.B. (1951) Observations on the general effects of injury in man. Spec. Rep. Ser. med. Res. Coun. No. 277, pp. 197, 198, 205 and 225.

HARDisty, R.M. \& Ingram, G.I.C. (1965) Bleeding Disorders, p. 148. Blackwell Scientific Publications, Oxford.

HARKINS, H.H. (1965) Surgery, Principles and Practice (Ed. by C. A. Moyer, J. E. Rhoades, J. G. Allen and H. N. Harkins), 3rd edn., p. 134. Pitman Medical, London.

HoвBS, J.T. (1966) Measurement of central venous pressure. Lancet, ii, 801.

JAMiESON, R.A. \& KAY, A.W. (1966) A Textbook of Surgical Physiology, p. 272. Livingstone, Edinburgh.
Lancet (1964) Dextrans for easing blood flow. Lancet, i, 28

Lancet (1966) Warm blood for massive transfusion. Lancet, i, 1193.

Lillehei, R.C., Longerbeam, J.K., Bloch, J.H. \& ManaX, W.G. (1964) The nature of irreversible shock. Ann. Surg. 160,682 .

MACLEAN, L.D. (1964) Blood volume versus central venous pressure in shock. Surg. Gynec. Obstet. 118, 594.

Maclean, L.D., Duff, J.H., Scott, H.M. \& Peretz, D.I. (1965) The treatment of shock in man based on haemodynamic diagnosis. Surg. Gynec. Obstet. $120,1$.

McGowan, G.K. \& WAlterX, G. (1963) The value of \& measuring central venous pressure in shock. Brit. J. Surg. 50, 821.

McGowan, G.K. \& Walters, G. (1966) A clinical study of $\overrightarrow{\vec{\omega}}$ surgical shock. Lancet, i, 611.

Mollison, P.L. (1967) Blood Transfusion in Clinical Medicine, 4th edn., pp. 153, 169, 175 and 177. Blackwell Scientific Publications, Oxford.

Morgan, T.O., LitTle, J.M. \& Evans, W.A. (1966) Renal failure associated with low molecular weight dextran. Brit. med. J. ii, 737.

MoYer, C.A. (1966) Surgery, Principles and Practice (Ed. C) by C. A. Moyer, J. E. Rhoads, J. G. Allen and H. N. o Harkins), 3rd edn., pp. 353 and 349. Pitman Medical, London.

Mueller, C.B. (1965) The mechanism of acute renal failure after injury and transfusion reaction and its prevention by solute diuresis. Surg. Clin. N. Amer. 45, 499.

Nadler, S.B., Hidalgo, J.U. \& Bloch, T. (1962) Prediction of blood volume. Surgery, 51, 224.

Nickerson, M. (1965) The Pharmacological Basis of Therapeutics, 3rd edn (Ed. by L. S. Goodman and A. Gilman), pp. 550 and 553. MacMillan, New York.

RicketTs, C.R. (1966) Molecular composition of transfusiof dextran. Brit. med. J. ii, 1423.

Saito, S., Smith, L.L., Saito, I. \& Hinshaw, D.B. (196\% Prevention and treatment of acute renal failure. Amer. $\vec{J}^{+}$ Surg. 110, 192.

SevirT, S. (1966) The boundaries between physiology, pathology and irreversibility after injury. Lancet, ii, 1203.

SHIRES, G.T. (1967) Shock and metabolism. Surg. Gynec. Obstet. 124, 2, 284.

SMITH, L.L. \& MOORE, F.D. (1962) Refractory hypotension in man-is this irreversible shock. New Engl. J. Med. 267, 733.

Teschan, P.E., Gagnon, J.A. \& Murphy, G.P. (1963) Renal function in hypotension with observations on the action of hypertonic mannitol. Clin. Res. 11, 241.

Topley, E. \& JACKSON, D.MACG. (1957) The clinical control of red cell loss in burns. J. clin. Path. 10, 1.

Wallace, A.B. (1951) The exposure treatment of burns Lancet, i, 501.

Wilkinson, A.W. (1960) Body Fluids in Surgery, 2nd edn, p. 124. Livingstone, Edinburgh.

Wilson, J.N., Grow, J.B., Demong, C.V., Prevedel, A.E. \& OWENS, J.C. (1962) Central venous pressure in optimal blood volume maintenance. Arch. Surg. (Chic.), 85, 563.

Wylie, W.D. \& ChuRChill-Davidson, H.C. (1966) $A$ Practice of Anaesthesia, 2nd edn, p. 514. Lloyd-Luke, London. 